\title{
Cortical threaded pedicle screw improves fatigue strength in decreased bone quality
}

\author{
Lukas Weiser $^{1} \mathbb{0} \cdot$ Kay Sellenschloh ${ }^{2} \cdot$ Klaus Püschel $^{3} \cdot$ Michael M. Morlock $^{2} \cdot$ Lennart Viezens $^{1} \cdot$ Wolfgang Lehmann $^{1}$. \\ Gerd Huber $^{2}$
}

Received: 24 March 2020 / Revised: 3 August 2020 / Accepted: 4 September 2020 / Published online: 17 September 2020

(c) The Author(s) 2020

\begin{abstract}
Purpose Inadequate anchoring of pedicle screws in vertebrae with poor bone quality is a major problem in spine surgery. The aim was to evaluate whether a modified thread in the area of the pedicle could significantly improve the pedicle screw fatigue strength.

Methods Fourteen human cadaveric vertebral bodies (L2 and L3) were used for in vitro testing. Bone density (BMD) was determined by quantitative computed tomography. Vertebral bodies were instrumented by standard pedicle screws with a constant double thread on the right pedicle and a partial doubling of the threads-quad thread-(cortical thread) in the area of the pedicle on the left pedicle. Pulsating sinusoidal, cyclic load $(0.5 \mathrm{~Hz})$ with increasing peak force $(100 \mathrm{~N}+0.1 \mathrm{~N} /$ cycles $)$ was applied orthogonal to the screw axis. The baseline force remained constant $(50 \mathrm{~N})$. Fatigue test was terminated after exceeding 5.4-mm head displacement $\left(\sim 20^{\circ}\right.$ screw tilting).

Results The mean fatigue load at failure was $264.9 \mathrm{~N}$ (1682 cycles) for the standard screws and was increased significantly to $324.7 \mathrm{~N}$ ( 2285 cycles) by the use of cortical threaded screws $(p=0.014)$. This effect is particularly evident in reduced BMD (standard thread $241.2 \mathrm{~N}$ vs. cortical thread $328.4 \mathrm{~N} ; p=0.016$ ), whereas in the group of vertebrae with normal BMD no significant difference could be detected (standard thread $296.5 \mathrm{~N}$ vs. cortical thread $319.8 \mathrm{~N} ; p=0.463$ ).

Conclusions Compared to a conventional pedicle screw, the use of a cortical threaded pedicle screw promises superior fatigue load in vertebrae with reduced bone quality.
\end{abstract}

Keywords Pedicle screw loosening $\cdot$ Pedicle screw design $\cdot$ Spine $\cdot$ BMD $\cdot$ Osteoporosis

\section{Introduction}

Pedicle screw instrumentation is a commonly used procedure in spinal surgery. Posterior stabilization is often necessary in spinal fractures, infections, degenerative cases, and tumor surgery [1]. Due to the demographic changes, the patients affected from spinal diseases are getting older and therefore the bone quality of the patients is getting worse [2].

Lukas Weiser

Lukas.Weiser@med.uni-goettingen.de

1 Department of Trauma Surgery, Orthopaedic Surgery and Plastic Surgery, University Medical Center Göttingen, Robert-Koch-Str. 40, 37099 Göttingen, Germany

2 Institute of Biomechanics, TUHH Hamburg University of Technology, Hamburg, Germany

3 Institute of Forensic Medicine, University Medical Center Hamburg-Eppendorf, Hamburg, Germany
It has been proven that the failure strength of pedicle screws directly correlates with the BMD of the vertebral body in which the screw is implanted [3-5] and loosening of pedicle screws is known to be the main reason for failure in posterior stabilization [3, 6-8]. There are several ways to increase the stability of a dorsal instrumentation, such as lengthening of the construct or cement augmentation of the pedicle screws [9-11]. However, lengthening is associated with a larger operation as well as loosening of adjacent motion segments and augmentation bears a high risk of complications such as leakage and subsequent embolism $[12,13]$.

Considering the stability of an implanted pedicle screw itself, it depends on the following three main factors: bone quality, implantation technique, and screw properties [14]. Most pedicle screws in clinical use are constant threaded with a coarse pitch as used in cancellous screws. However, it has been shown that the cortical bone in the pedicle provides 
more than $80 \%$ of the cranio-caudal stiffness and takes over almost $60 \%$ of the pullout strength of pedicle screws, whereas the stabilizing effect of the cancellous bone is not as important [15]. It has to be suspected that a fine pitch thread in the area of the pedicle could improve the mechanical performance of the screw junction. However, fine pitch thread, created by adding an additional thread in the area of the pedicle, was investigated in pullout and FE models, but it was not possible to identify a clear advantage of a cortical threaded screw over a conventional threaded screw in those studies [16-18].

The aim was to exhibit whether a pedicle screw with proximal doubling of the threads (cortical thread) is ahead of a standard conventional threaded pedicle screw in vertebral bodies with low bone quality.

\section{Materials and methods}

In total, 14 human cadaveric vertebral bodies (L2 and L3) were collected from eight donors (three females/five males) aged between 52 and 70 years (mean \pm SD: $61 \pm 7$ years). After harvesting, the specimens were sealed in plastic bags and stored below $-20^{\circ} \mathrm{C}$. CT scans of all specimens using a 16-row CT scanner (Brilliance 16 CT; Philips Healthcare, Hamburg, Germany) were performed, and each vertebral body was screened for prior fractures. All scans contained a solid calibration phantom (Bone Density Calibration Phantom; QRM, Moehrendorf, Germany) to enable subsequent determination of the apparent volumetric bone mineral density (vBMD) in terms of mg calcium hydrogen carbonate per $\mathrm{cm}^{3}$. This was done by linearly converting the Hounsfield unit (HU) value, measured in a defined three-dimensional cube in the center of each vertebral body, to the phantom's reference densities (Avizo 5.1, VSG Inc., Burlington, Massachusetts).

The mean BMD of all vertebral bodies was $109.3 \mathrm{mg} /$ $\mathrm{cm}^{3}$ (SD: $28.6 \mathrm{mg} / \mathrm{cm}^{3}$ ). Eight vertebral bodies showed an osteopenic/osteoporotic bone quality with an average BMD of $89.1 \mathrm{mg} / \mathrm{cm}^{3}$ (SD: $16.4 \mathrm{mg} / \mathrm{cm}^{3}$ ), while six vertebral bodies had normal bone quality $\left(136.2 \pm 15.4 \mathrm{mg} / \mathrm{cm}^{3}\right)$ [19] (Table 1).

The specimens were defrosted the night before testing at room temperature, and single vertebral bodies were dissected. Throughout preparation, specimens were sprayed with Ringer solution and wrapped in moist tissue in order to preserve humid tissue constitution. One pedicle of each vertebral body was instrumented by commercially available standard polyaxial double-threaded screws (6.0 mm $\times 45$ mm, Expedium, DePuy Synthes Inc., West Chester, PA, USA), while the second pedicle was instrumented with a partial quad-threaded (cortical threaded) screw (6.0 mm $\times 45 \mathrm{~mm}, \mathrm{CFX}$, DePuy Synthes Inc., West
Table 1 Data on specimens including donor age and sex, segmental level, and the respective BMD

\begin{tabular}{llllll}
\hline Donor & Specimen & Age & Sex & $\begin{array}{l}\text { Segmen- } \\
\text { tal level }\end{array}$ & BMD $\left(\mathrm{mg} / \mathrm{cm}^{3}\right)$ \\
\hline 1 & 1 & 66 & M & L3 & 122.7 \\
2 & 2 & 55 & F & L3 & 161.6 \\
3 & 3 & 53 & M & L3 & 122.5 \\
3 & 4 & 53 & M & L2 & 128.7 \\
4 & 5 & 67 & M & L3 & 98.9 \\
4 & 6 & 67 & M & L2 & 99.2 \\
5 & 7 & 70 & M & L3 & 53.3 \\
5 & 8 & 70 & M & L2 & 106.8 \\
6 & 9 & 64 & M & L3 & 135.0 \\
6 & 10 & 64 & M & L2 & 146.5 \\
7 & 11 & 52 & F & L3 & 91.8 \\
7 & 12 & 52 & F & L2 & 88.5 \\
8 & 13 & 60 & F & L3 & 81.4 \\
8 & 14 & 60 & F & L2 & 93.3 \\
\hline
\end{tabular}

Chester, PA, USA) (Fig. 1). The standard screw is double threaded, which means it has two leads. Consequently, the pitch is twice the distance of adjacent threads. The cortical screw has a tip area that is complete the same as the standard screws, but its shaft (18 $\mathrm{mm}$ from the head of the screw) is equipped with a quad thread. This means that the part that will be in contact with the pedicles has two additional threads in between the two standard threads.

Screws were inserted parallel to the vertebral endplate according to the Weinstein method [20] under fluoroscopic guidance (Fig. 2). Subsequently, the specimens were embedded in an aluminum fixture using polyurethane resin (RenCast FC 52/53, Huntsman Inc., Salt Lake City, UT, USA). The cavity of the fixture enabled embedding from the anterior to the posterior border of the vertebral body. The posterior arch and pedicle remained completely free (Fig. 3).

\section{Mechanical setup}

The outer surface of the embedding was spherical to enable exact horizontal positioning of the screws on top of a $x-y$-table on a servo-hydraulic testing machine (MTS 858.2, MTS Systems, Eden Prairie, MN, USA). The screw heads were linked to the connecting frame of the setup using a short rod of $2 \mathrm{~cm}$ length (Expedium titanium $5.5 \mathrm{~mm}$, DePuy Synthes Inc., West Chester, PA, USA) and a blocker screw (Expedium Single Innie, DePuy Synthes Inc., West Chester, PA, USA). The rotational axis of the connecting frame pointed exactly through the screw head, allowed rotation with one degree of freedom orthogonal to the screw axis (Fig. 3). Thus, the pivot point of the screw is located exactly in line with the screw head and orthogonal to the screw axis, which 
Fig. 1 Standard pedicle screw with a double thread and cortical threaded pedicle screw with partial quad thread
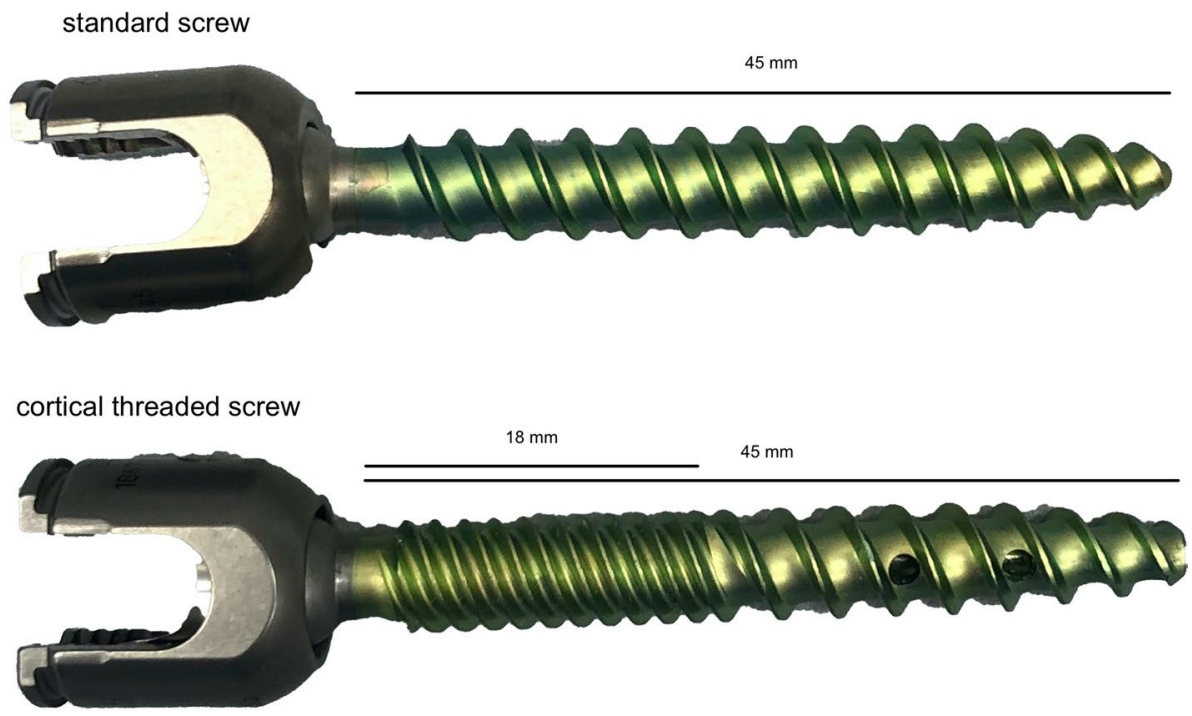

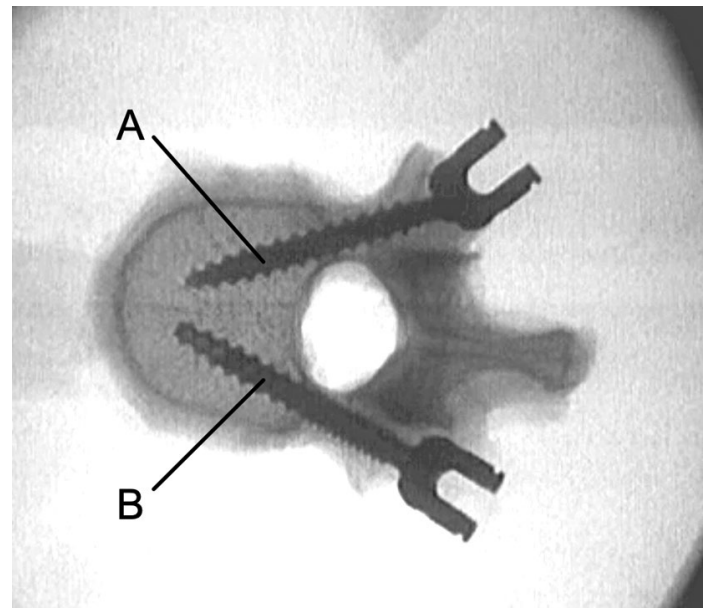

Fig. 2 Axial X-ray showing the vertebral body after instrumentation with a standard screw on one side (a) and a cortical threaded screw on the other side (b)

enables toggling of the screw as a result of the translation of the screw head. Moreover, the loading axis of the test setup was positioned in line with the sphere of the screw head, so that no moment was transferred to the screw head, which prevented the head from tilting with respect to the poly-axial screw.

Fatigue testing was performed by applying a caudal sinusoidal, cyclic $(0.5 \mathrm{~Hz})$ force. The initial cycle ranged from 50 to $100 \mathrm{~N}$ which represented the load during physiological walking [21]. The baseline force remained $50 \mathrm{~N}$, while the peak load was stepwise increased by $0.1 \mathrm{~N}$ every cycle (Locati test design) [22]. This continuous increasing was chosen to accelerate failure and hereby reduce the effects of degradation of the specimen. Testing was stopped when the displacement of the center of the screw heads achieved $5.4 \mathrm{~mm}$ (approximately $20^{\circ}$ tilting of the screws). Testing of the conventional threaded and cortical threaded screws was carried out separately, starting first alternately with the conventional threaded or cortical threaded screw.

\section{Measured parameters}

The maximum force (fatigue load) and number of completed cycles at the end of the cyclic loading (at 5.4-mm caudal displacement of the screw head) were logged, and the construct stiffness at the beginning and at the end of the testing was determined (MATLAB, The MathWorks Inc., Natick, MA, USA). Additionally, loosening was visually evaluated (no scoring system) based on subsequently performed CT scans. Furthermore, the removal torque of each screw was measured (Torsiometer 760, Stahlwille, Wuppertal, Germany) to verify that loosening of the screws occurred.

\section{Statistical analysis}

The fatigue load of the two screw types was compared using parametric one-way analysis of variance (ANOVA). The stiffness values and the removal torque were investigated using nonparametric Mann-Whitney U-test analyses. A linear regression analysis was performed to investigate the influence of BMD and age on the fatigue load. Significance of the regression was tested using an ANOVA. The type I error probability was set to $\alpha=0.05$ (SPSS, version 21, IBM, Armonk, NY, USA).

\section{Results}

The fatigue testing produced a pattern of failure with a caudal displacement of the screw head and a cranial displacement of the screw tip. The center of rotation of the loosening 
Fig. 3 In the test setup, the specimens were embedded in a custom-made, spherical fixture which was positioned on top of a $x-y$-table. The fixture enabled an exactly horizontal orientation of the screws. The screw was linked to a connecting frame, whose rotational axis was aligned to the screw headallowed movement with one degree of freedom perpendicular to the screw direction. Load was applied in caudal direction

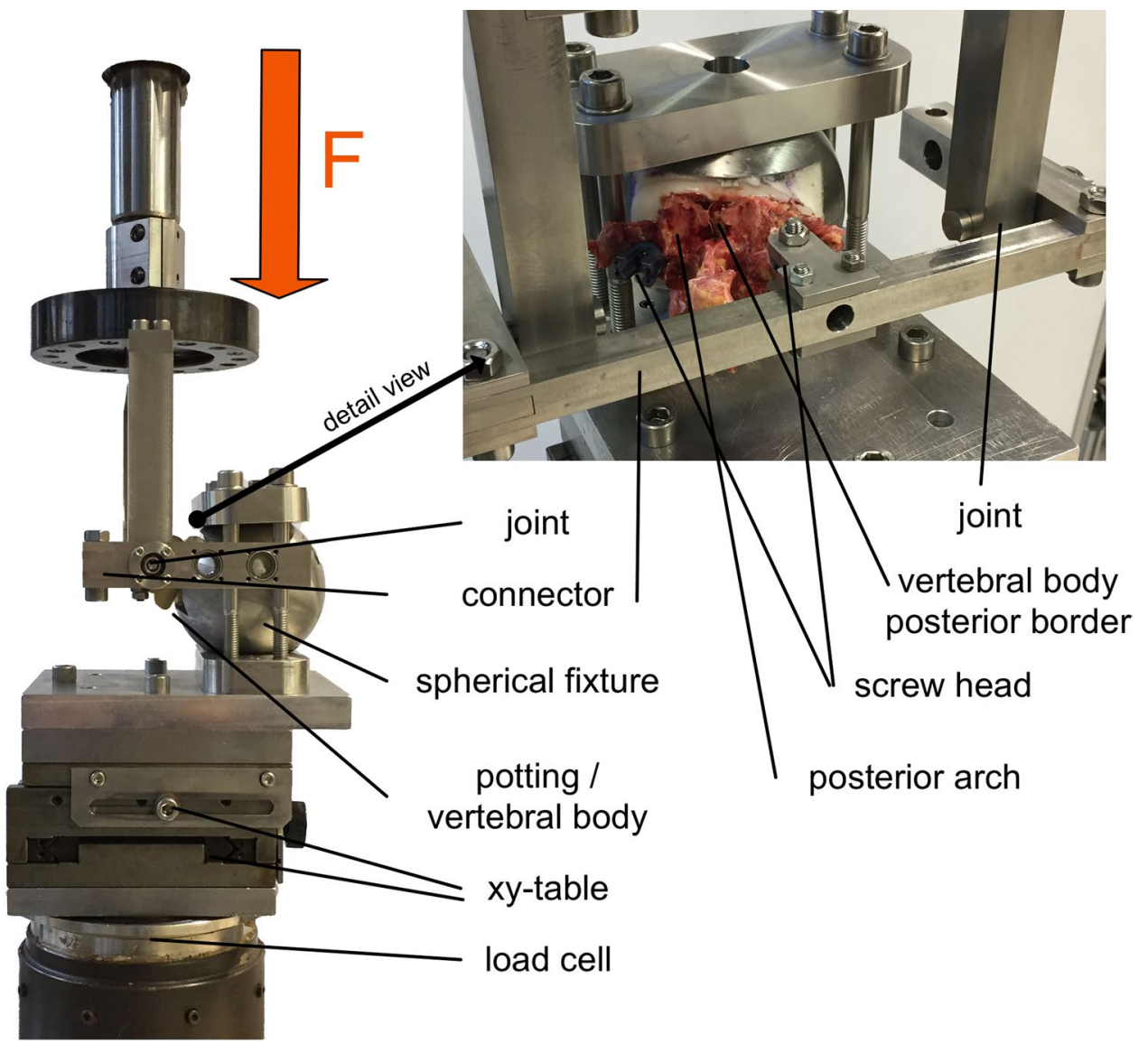

area in the vertebral body laid in the middle section of the pedicle and a widening of the entrance point into the pedicle was observed (Fig. 4). The visual screening of the specimens after testing showed a loosening (dislocation of the screw head caudally, widening of the screw entry point, tilting of the screw in the vertebral body) of all screws, and there was no tilting of the screw heads with respect to connection rod. The removal torque was less or equal to $0.50 \mathrm{Nm}$ in all cases. There was no significant difference between the removal torque of the standard screw and the cortical threaded screws (standard screw: $0.26 \pm 0.09 \mathrm{Nm}$; cortical threaded screw: $0.35 \pm 0.12 \mathrm{Nm} ; p=0.077)$.

The stiffness of the screw-vertebra constructs with standard screws, measured at the beginning of testing, did not differ significantly compared to the constructs with cortical threaded screws (standard screw: $280.9 \pm 60.7 \mathrm{~N} / \mathrm{mm}$; cortical threaded screw: $329.5 \pm 26.9 \mathrm{~N} / \mathrm{mm} ; p=0.114)$. At the end of testing, the cortical threaded screw constructs exhibited a significantly higher stiffness (standard screw: $227.7 \pm 36.9 \mathrm{~N} / \mathrm{mm}$; cortical threaded screw: $256.3 \pm 39.7 \mathrm{~N} /$
Fig. 4 A specimen after testing showing widening of the entrance point into the pedicle. CT scan demonstrating an extended screw channel with center of rotation in the area of the pedicle

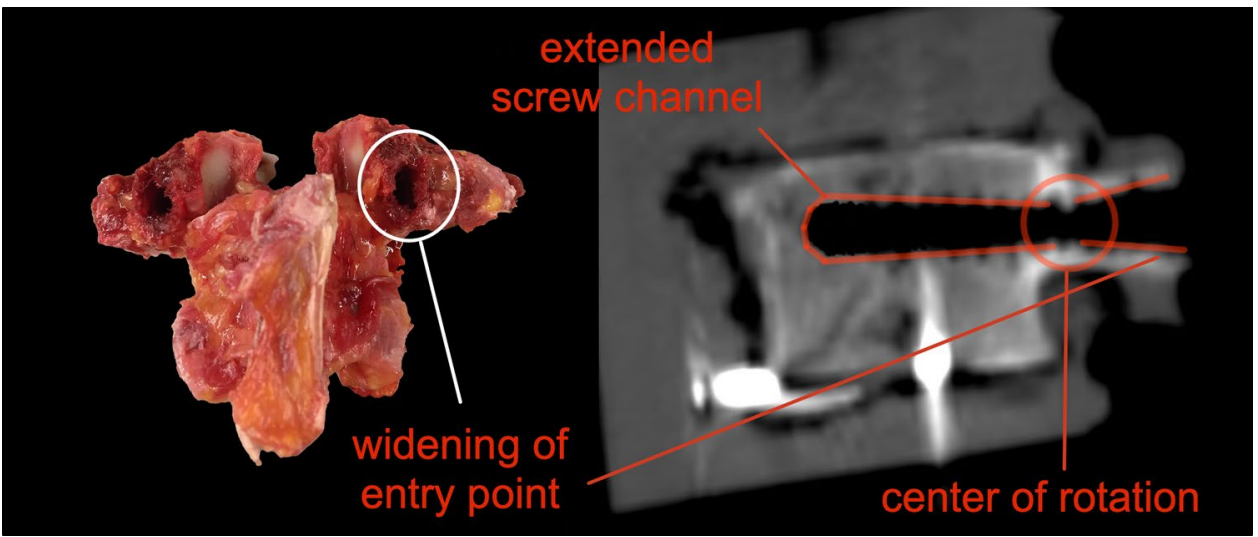


Table 2 Stiffness of standard screw construct and cortical threaded screws construct at the start and at the end of testing (mean and SD)

\begin{tabular}{lllllll}
\hline Stiffness & Start & & & End & & $p$ value \\
\cline { 2 - 3 }$(\mathrm{N} / \mathrm{mm})$ & Mean & $\mathrm{SD}$ & & Mean & SD & \\
\hline Standard screw & 280.9 & 60.7 & 227.7 & 36.9 & $\mathbf{0 . 0 1 2}$ \\
Cortical threaded screw & 329.5 & 26.9 & 256.3 & 39.7 & $\mathbf{0 . 0 0 2}$ \\
$p$ value & 0.114 & & $\mathbf{0 . 0 0 5}$ & & \\
\hline
\end{tabular}

$P$ values for the comparison between stiffness at start and end of testing and for the comparison of standard screw versus cortical threaded screws

Bold indicates significant $p$ values $(<0.05)$

$\mathrm{mm} ; p=0.005)$. In both groups, the stiffness decreased significantly during testing (Table 2).

The fatigue load was $264.9 \mathrm{~N}$ (SD: $53.4 \mathrm{~N}$ )—corresponding to 1682 cycles (SD: 538) - for the standard screws, while the cortical threaded screws sustained $324.7 \mathrm{~N}$ (SD: $62.6 \mathrm{~N}$ )—corresponding to 2285 cycles (SD: 629) until failure, which was significantly higher $(p=0.014)$. Looking separately at the results from the osteopenic/osteoporotic vertebrae $(n=8)$ and the vertebrae with normal BMD $(n=6)$, it appears that the higher fatigue load and cycles to failure of the cortical threaded screws only show up in osteopenic/osteoporotic vertebrae $(p=0.016)$, while there was no significant difference in vertebral bodies with normal bone density $(p=0.463)$ (Fig. 5; Table 3). Considering the correlation between bone mineral density and fatigue load, it can be seen that the fatigue load of the standard screws tends to be closer related to bone density than the fatigue load of the cortical threaded screws; however, there was no significant correlation (standard screw: $R^{2}=0.28, p=0.052$; cortical threaded screw: $R^{2}=0.01, p=0.731$ ). According to this, the stability of the standard screws is inadequate, especially in the osteopenic/osteoporotic vertebrae, while the cortical threaded screws also find a good anchorage (Fig. 6).

Furthermore, there was a significant correlation between specimen age and fatigue load (standard screw: $r=-0.580, p=0.030$; cortical threaded screw: $r=-0.726, p=0.003$ ), while the sex showed no significant
Fig. 5 Box plot showing the fatigue load for standard and cortical threaded screws separately for vertebral bodies with a BMD $<120 \mathrm{mg} / \mathrm{cm}^{3}$ and $\mathrm{BMD}>120 \mathrm{mg} / \mathrm{cm}^{3}$. The $p$-value is given for the comparison between standard and cortical threaded screws
Table 3 Results of fatigue load for standard double-threaded and partial quad-threaded screws

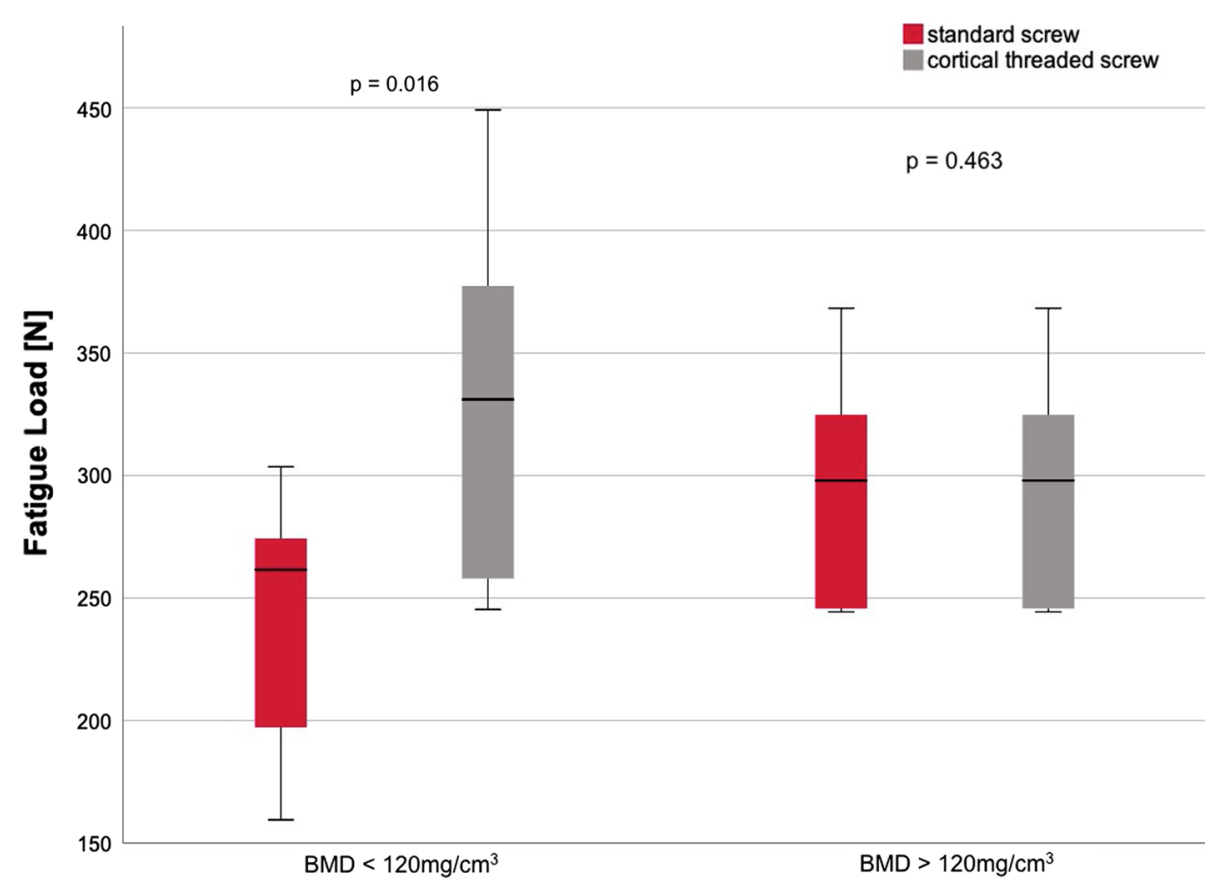

\begin{tabular}{|c|c|c|c|c|c|c|}
\hline \multirow[t]{2}{*}{ Fatigue load $[N]$} & \multicolumn{2}{|c|}{ All vertebrae } & \multicolumn{2}{|c|}{ Normal BMD } & \multicolumn{2}{|c|}{$\begin{array}{l}\text { Osteopenic/osteo- } \\
\text { porotic BMD }\end{array}$} \\
\hline & Mean & SD & Mean & SD & Mean & SD \\
\hline Standard screw & 264.9 & 53.4 & 296.5 & 47.6 & 241.2 & 50.8 \\
\hline Cortical threaded screw & 324.7 & 62.6 & 319.8 & 57.4 & 328.4 & 73.8 \\
\hline$p$ value & 0.014 & & 0.463 & & 0.016 & \\
\hline
\end{tabular}

Bold indicates significant $p$ values $(<0.05)$ 
Fig. 6 Correlation of fatigue load and BMD for the standard screws and the cortical threaded pedicle screws

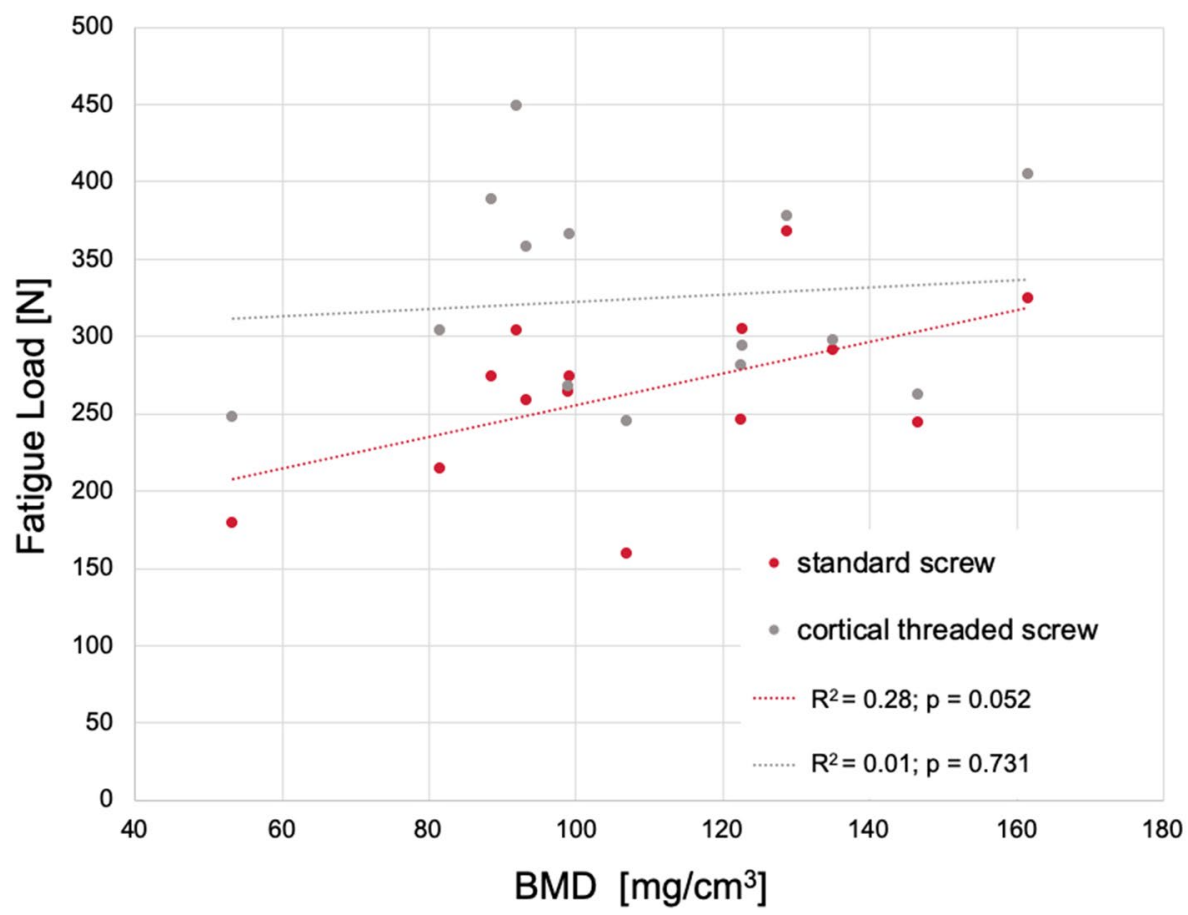

influence on the failure load (standard screw $p=0.699$; cortical threaded screw $p=0.012$ ).

\section{Discussion}

Demographic change is leading to a further increase in the number of elderly patients. Dorsal stabilization using pedicle screws is a standard procedure in the field of spinal surgery in these patients. However, the BMD, which is known to be crucial for pedicle screw stability, decreases with age, and therefore, loosening of pedicle screws is the main reason for failure in posterior stabilization [3, 6-8]. In this study, the fixation of pedicle screws with different thread designs was investigated. It was examined whether doubling the threads in the area of the pedicle could significantly improve the anchorage of the screw in the vertebral body and how the bone density affects this. Using a fatigue toggling testing setup, loading conditions were applied, which are believed to be more clinically relevant compared with pullout [22, 23].

Hirano et al. showed that the stability of pedicle screws mainly depends on cortical bone in the pedicle, whereas the stabilizing effect of the cancellous bone is not as important [15]. However, the standard pedicle screws are designed with a coarse pitch as used in cancellous screws. Accordingly, we see a close association of pedicle screw stability with bone mineral density in the vertebral body and inadequate stability with poor bone quality [4]. Assuming that the cortical anchoring of a screw in the pedicle is essential and that this area is not as much affected by a bone density reduction compared to the cancellous part of the vertebral body, it seems reasonable to optimize the anchoring of the screw exactly in this area.

There are few studies dealing with the influence of screw design on pedicle screw stability. Brasiliense et al. investigated the pullout force and fatigue endurance using cadaveric vertebral bodies and foam blocks and did not exhibit significant difference between single-threaded and dual-threaded screws. This was probably due to a small sample size and the bone density of the specimens used. Mummaneni et al. investigated the pullout force of single vs. double-threaded pedicle screws in cadaveric vertebral bodies [24]. However, they used double-threaded screws with alternating thread heights through the entire screw length and a second parallel thread of lower height. They concluded that a second, smaller, inner thread on a double-threaded pedicle screw does cause neither increased bone purchase nor higher pullout strengths [24].

In this study, a testing setup with a repeating stepwise increasing force, within the physiological range [21], was used. This resulted in an in vivo-like failure pattern with cranio-caudal loosening of the pedicle screws. Furthermore, during testing a continuous decrease in stiffness was observed. This is most probably caused by successive damage to the trabecular bone and in turn leads to loosening of the screw. This is in accordance with the study of Kiner et al. who showed that the loss of stiffness due to testing is a parameter to quantify the damage to the trabecular bone [25]. A caudal displacement of the screw head of $5.4 \mathrm{~mm}$ 
was set as indication to terminate the test. This corresponds to a tilt of the screw in the vertebral body of approximately $20^{\circ}$ [22]. On the basis of this criterion, it is not possible to determine complete loosening in all sense, but it can be assumed that severe loosening has certainly occurred by this time. Furthermore, the very low removal torque, measured for all screws, is another clear sign for loosening of all screws during testing.

Although we could not demonstrate a significant correlation between bone density and fatigue load for both the standard screw and the cortical threaded screw, it can be supposed that partial quad lead pedicle screws tend to be less dependent on bone density as the stability of conventional threaded (dual lead) pedicle screws. On the one hand, the correlation between bone density and fatigue load is much more pronounced for the standard screw, even if it is not significant. On the other hand, there is a significant difference regarding the fatigue load between the two screw types only depending on the bone density. This thesis is consistent with the fact that a decrease in bone density essentially affects the trabecular bone. The cortical threaded screw aims for an optimal cortical anchoring in the pedicle, so that the influence of the bone density should be less decisive here. Subsequently, doubling the threads of a pedicle screw in the area of the pedicle, resulting in a fine pitch as known from cortical screws, leads to a significant increase in stability in vertebral bodies with low bone density.

Considering the risks of other methods to improve the stability of a posterior instrumentation, such as cement augmentation or lengthening, the use of a screw with optimal anchoring in the vertebral body seems to be meaningfuleven if combined with additional procedures in case needed.

This study is limited by the relatively small sample size, due to the restricted availability of human specimens. However, due to the use of human specimens the study is much closer to in vivo conditions compared to sawbone or PU foam studies. The biomechanical cadaver model is not able to replicate in vivo conditions with respect to screw ingrowth and multidirectional loading. In this in vitro experiment, the load was applied through the screw head, which does not exactly reflect the complex in vivo situation where multiaxial load is also applied through the vertebral body [21, 26]. However, the most relevant loading direction (according to Rohlmann et al. [21]) was applied in a standardized and reproducible manner. This might explain why the loosening observed in the post testing CT, with a rotation center in the area of the pedicle, differs from studies with complex loading conditions, which describe a shifting of the center of rotation toward the screw tip during testing [27]. However, in order to compare two different types of thread these simplifications were made to increase the selectivity of the in vitro experiment-especially with regard to the limited availability of specimens. Another common limitation is that the variation of the size of the vertebral bodies from human specimens was not taken into account. Therefore, the screw diameter was not adapted to the specimen's pedicle width according to clinical routine. Furthermore, variations in the screw orientation and screw entry point may also have influenced the results. Only standard pedicle screws, implanted using the Weinstein method [20], were examined, and no statement can be made regarding other screw trajectories. The insertion torque was not measured during screw implantation so that we cannot make a statement regarding the torque before loosening or compare the removal torque with the insertion torque. The insertion process was kept in accordance with the clinical praxis.

In summary, a modified thread in the area of the pedicle can significantly influence the stability of pedicle screws in vertebral bodies. This influence depends on the bone mineral density. Therefore, a partial quad-threaded pedicle screw leads to a significant increase in fatigue load compared to a standard double-threaded pedicle screw in the presence of reduced bone quality.

Funding Open Access funding enabled and organized by Projekt DEAL.

\section{Compliance with ethical standards}

Conflict of interest The authors declare that they have no conflict of interest.

Open Access This article is licensed under a Creative Commons Attribution 4.0 International License, which permits use, sharing, adaptation, distribution and reproduction in any medium or format, as long as you give appropriate credit to the original author(s) and the source, provide a link to the Creative Commons licence, and indicate if changes were made. The images or other third party material in this article are included in the article's Creative Commons licence, unless indicated otherwise in a credit line to the material. If material is not included in the article's Creative Commons licence and your intended use is not permitted by statutory regulation or exceeds the permitted use, you will need to obtain permission directly from the copyright holder. To view a copy of this licence, visit http://creativecommons.org/licenses/by/4.0/.

\section{References}

1. Dickman CA, Fessler RG, MacMillan M, Haid RW (1992) Transpedicular screw-rod fixation of the lumbar spine: operative technique and outcome in 104 cases. J Neurosurg 77:860-870. https ://doi.org/10.3171/jns.1992.77.6.0860

2. Xu Y, Wu Q (2018) Decreasing trend of bone mineral density in US multiethnic population: analysis of continuous NHANES 2005-2014. Osteoporos Int 29:2437-2446. https://doi. org/10.1007/s00198-018-4648-9

3. Halvorson TL, Kelley LA, Thomas KA, Whitecloud TS 3rd, Cook SD (1994) Effects of bone mineral density on pedicle screw fixation. Spine (Phila Pa 1976) 19:2415-2420 
4. Weiser L, Huber G, Sellenschloh K, Viezens L, Puschel K, Morlock MM, Lehmann W (2017) Insufficient stability of pedicle screws in osteoporotic vertebrae: biomechanical correlation of bone mineral density and pedicle screw fixation strength. Eur Spine J. https://doi.org/10.1007/s00586-017-5091-x

5. Wittenberg RH, Shea M, Swartz DE, Lee KS, White AA 3rd, Hayes WC (1991) Importance of bone mineral density in instrumented spine fusions. Spine (Phila Pa 1976) 16:647-652

6. Galbusera F, Volkheimer D, Reitmaier S, Berger-Roscher N, Kienle A, Wilke HJ (2015) Pedicle screw loosening: a clinically relevant complication? Eur Spine J 24:1005-1016. https://doi. org/10.1007/s00586-015-3768-6

7. Paxinos O, Tsitsopoulos PP, Zindrick MR, Voronov LI, Lorenz MA, Havey RM, Patwardhan AG (2010) Evaluation of pullout strength and failure mechanism of posterior instrumentation in normal and osteopenic thoracic vertebrae. J Neurosurg Spine 13:469-476. https://doi.org/10.3171/2010.4.SPINE09764

8. Wu ZX, Gong FT, Liu L, Ma ZS, Zhang Y, Zhao X, Yang M, Lei W, Sang HX (2012) A comparative study on screw loosening in osteoporotic lumbar spine fusion between expandable and conventional pedicle screws. Arch Orthop Trauma Surg 132:471-476. https://doi.org/10.1007/s00402-011-1439-6

9. Hoppe S, Keel MJ (2017) Pedicle screw augmentation in osteoporotic spine: indications, limitations and technical aspects. Eur J Trauma Emerg Surg 43:3-8. https://doi.org/10.1007/s0006 8-016-0750-x

10. Pekmezci M, Herfat S, Theologis AA, Viscogliosi P, Demirkiran G, McClellan RT, Ames C (2015) Integrity of damage control posterior spinal fusion constructs for patients with polytrauma: a biomechanical investigation. Spine (Phila Pa 1976) 40:E12191225. https://doi.org/10.1097/BRS.0000000000001058

11. Weiser L, Dreimann M, Huber G, Sellenschloh K, Puschel K, Morlock MM, Rueger JM, Lehmann W (2016) Cement augmentation versus extended dorsal instrumentation in the treatment of osteoporotic vertebral fractures: a biomechanical comparison. Bone Jt J 98-B:1099-1105. https://doi.org/10.1302/0301-620X.98B8.37413

12. Guo HZ, Tang YC, Guo DQ, Zhang SC, Li YX, Mo GY, Luo PJ, Zhou TP, Ma YH, Liang JXB (2019) The cement leakage in cement-augmented pedicle screw instrumentation in degenerative lumbosacral diseases: a retrospective analysis of 202 cases and 950 augmented pedicle screws. Eur Spine J 28:1661-1669. https ://doi.org/10.1007/s00586-019-05985-4

13. Janssen I, Ryang YM, Gempt J, Bette S, Gerhardt J, Kirschke JS, Meyer B (2017) Risk of cement leakage and pulmonary embolism by bone cement-augmented pedicle screw fixation of the thoracolumbar spine. Spine J. https://doi.org/10.1016/j.spine e.2017.01.009

14. Cho W, Cho SK, Wu C (2010) The biomechanics of pedicle screw-based instrumentation. J Bone Joint Surg Br 92:1061-1065. https://doi.org/10.1302/0301-620X.92B8.24237

15. Hirano T, Hasegawa K, Takahashi HE, Uchiyama S, Hara T, Washio T, Sugiura T, Yokaichiya M, Ikeda M (1997) Structural characteristics of the pedicle and its role in screw stability. Spine (Phila Pa) 22:2504-2509. https://doi.org/10.1097/00007632199711010-00007

16. Brasiliense LB, Lazaro BC, Reyes PM, Newcomb AG, Turner JL, Crandall DG, Crawford NR (2013) Characteristics of immediate and fatigue strength of a dual-threaded pedicle screw in cadaveric spines. Spine J 13:947-956. https://doi.org/10.1016/j.spine e.2013.03.010
17. Mehta H, Santos E, Ledonio C, Sembrano J, Ellingson A, Pare P, Murrell B, Nuckley DJ (2012) Biomechanical analysis of pedicle screw thread differential design in an osteoporotic cadaver model. Clin Biomech (Bristol, Avon) 27:234-240. https://doi. org/10.1016/j.clinbiomech.2011.10.004

18. Takenaka S, Kaito T, Ishii K, Watanabe K, Watanabe K, Shinohara A, Harada T, Nakada F, Majima Y, Matsumoto M (2019) Influence of novel design alteration of pedicle screw on pullout strength: a finite element study. J Orthop Sci. https://doi. org/10.1016/j.jos.2019.03.002

19. American College of Radiology (2014) ACR-SPR-SSR practice parameter for the performance of quantitative computed tomography (QCT) bone densitometry. https://www.acr.org/ /media/ACR/ Documents/PGTS/guidelines/QCT.pdf

20. Weinstein JN, Spratt KF, Spengler D, Brick C, Reid S (1988) Spinal pedicle fixation: reliability and validity of roentgenogram-based assessment and surgical factors on successful screw placement. Spine (Phila Pa) 13:1012-1018. https://doi. org/10.1097/00007632-198809000-00008

21. Rohlmann A, Bergmann G, Graichen F (1997) Loads on an internal spinal fixation device during walking. J Biomech 30:41-47. https://doi.org/10.1016/s0021-9290(96)00103-0

22. Kueny RA, Kolb JP, Lehmann W, Puschel K, Morlock MM, Huber $G$ (2014) Influence of the screw augmentation technique and a diameter increase on pedicle screw fixation in the osteoporotic spine: pullout versus fatigue testing. Eur Spine J 23:2196-2202. https://doi.org/10.1007/s00586-014-3476-7

23. Bostelmann R, Keiler A, Steiger HJ, Scholz A, Cornelius JF, Schmoelz W (2017) Effect of augmentation techniques on the failure of pedicle screws under cranio-caudal cyclic loading. Eur Spine J 26:181-188. https://doi.org/10.1007/s00586-015-3904-3

24. Mummaneni PV, Haddock SM, Liebschner MA, Keaveny TM, Rosenberg WS (2002) Biomechanical evaluation of a doublethreaded pedicle screw in elderly vertebrae. J Spinal Disord Tech 15:64-68

25. Kiner DW, Wybo CD, Sterba W, Yeni YN, Bartol SW, Vaidya R (2008) Biomechanical analysis of different techniques in revision spinal instrumentation: larger diameter screws versus cement augmentation. Spine (Phila Pa) 33:2618-2622. https:// doi.org/10.1097/BRS.0b013e3181882cac

26. Wilke HJ, Kaiser D, Volkheimer D, Hackenbroch C, Puschel K, Rauschmann M (2016) A pedicle screw system and a lamina hook system provide similar primary and long-term stability: a biomechanical in vitro study with quasi-static and dynamic loading conditions. Eur Spine J 25:2919-2928. https://doi.org/10.1007/ s00586-016-4679-x

27. Liebsch C, Zimmermann J, Graf N, Schilling C, Wilke HJ, Kienle A (2018) In vitro validation of a novel mechanical model for testing the anchorage capacity of pedicle screws using physiological load application. J Mech Behav Biomed Mater 77:578-585. https ://doi.org/10.1016/j.jmbbm.2017.10.030

Publisher's Note Springer Nature remains neutral with regard to jurisdictional claims in published maps and institutional affiliations. 